\title{
LA SITUACIÓN DE LOS INMIGRANTES EN LOS PAÍSES DE ACOGIDA: PROBLEMÁTICA DE LA INTEGRACIÓN
}

\author{
MOHAMED KHACHANI
}

Universidad Mohamed V Agdal, Rabat (Marruecos). Asociación Marroquí de Estudios e Investigaciones sobre las Migraciones (AMERM).

\section{RESUMEN}

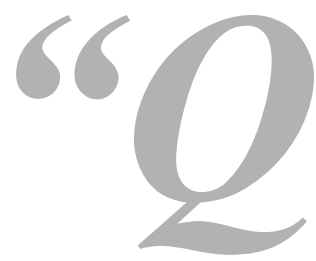

uerían brazos, han recibido hombres". Así resumía el sociólogo francés Alain Touraine la problemática de la integración. Ésta sigue siendo una cuestión muy amplia y muy compleja; compleja porque el estatus del inmigrante y su condición varían en función de varios parámetros. La integración de los emigrantes nos lleva a una problemática de diferentes niveles. En primer lugar, plantea un problema de conceptualización: ¿qué es la integración? Seguidamente, requiere una presentación de los sujetos de la integración, grupo heteróclito cuya heterogeneidad se sitúa a varios niveles: la nacionalidad, el entorno de origen, la edad, el sexo, el nivel educativo, lo cual nos lleva a un análisis cuantitativo y cualitativo de la población inmigrante. El tercer aspecto hace referencia a los espacios de la integración: el espacio económico, político, social y cultural, y, por último, a los obstáculos para la integración, es decir, todas las presiones a las que se enfrentan los inmigrantes en las sociedades de acogida y, en particular, en España.

Palabras clave: inmigración, integración, discriminación.

\section{ABSTRACT: The situation of immigrants in their host countries: the problem of integration.}

This article looks at the problems of integration experienced by immigrants from the Maghreb. Economic, social, political and cultural aspects all influence integration. In the labour market, immigrants tend to target sectors which demand minimal professional qualifications and offer salaries below those of the non-immigrant population. In the social arena, two aspects stand out; schooling and housing. The children of immigrants experience difficulties at school due to material and social conditions, but also as a result of cultural diversity. As regards housing, immigrants tend to gravitate towards certain neighbourhoods which, at times, can give rise to the impression of an "invasion". In the political sphere, the possibility of participation is limited, leading to the situation of "less rights", unless the host country's nationality 
is adopted, which in itself does not guarantee better integration. The right to culture receives less recognition, but nevertheless has a significant effect on integration. The main obstacles to integration are located in the labour market and in social discrimination. Lastly, reference is made to the situation of these immigrants in Spain.

Key words: Immigration, integration, discrimination.

CORRESPONDENCIA:

Mohamed Khachani

Université Mohamed V, Agdal, Rabat. Faculté des Sciences Juridiques, Economiques et Sociales.

Avenue des Nations Unies, Agdal, BP: 721 Rabat. Maroc. 


\section{EL ENFOQUE CONCEPTUAL}

Este enfoque exige una distinción fundamental entre dos conceptos a menudo sujetos a confusión y cuyo significado es distinto: la asimilación y la integración.

1. La asimilación se puede definir como "el proceso por el cual una o varias personas renuncian a su cultura de origen para adoptar seguidamente las costumbres del país de acogida, por definición distintas a las suyas". En Francia, el informe del diputado Michel Hannoun (Rassemblement pour la République-Agrupación para la República-) ofrece una definición oficial de la asimilación, que "pretende borrar todas las diferencias. Asimilar es convertir en similar a sí mismo. Esto implica una obligación: exigir a los demás y, en particular, a los extranjeros que abandonen sus valores para fundirse en el molde uniforme".

Desde este punto de vista, "inmigrar no es solamente cambiar de lugar geográfico, sino también cambiar de Historia”. Algunos de los que defienden esta opción son, por ejemplo, los conservadores neerlandeses que quieren, según dicen, un país "homogéneo" y consideran perjudicial la diversidad cultural ${ }^{1}$.

Así pues, la asimilación supone la dilución en la sociedad de acogida y esa negación es lo que frena este movimiento en la comunidad marroquí.

2. La integración, sin embargo, tiene otro significado. Retomando las categorías de Emile Durkheim, los tres elementos significativos de un verdadero proceso de integración social son la solidaridad, la cohesión y la interdependencia. Sólo a través de la apertura (acogida, respeto) hacia el otro (el inmigrante, el extranjero, el diferente) y de su adopción puede una sociedad fundar su cohesión interna, aceptando el mantenimiento de determinadas diferencias, de una determinada especificidad de las poblaciones inmigrantes y consintiendo la dinámica racional del intercambio, de la interdependencia, como camino para resolver los conflictos inevitables de todo encuentro.

Por tanto, la integración supone compartir cierto número de valores fundamentales y el deseo de participar en la edificación de un conjunto nacional. Supone, asimismo, una interacción cultural en la que cada uno extraerá de la otra cultura elementos que puedan acercar a los seres y a las culturas. Sin embargo, la adquisición de estos elementos puede extenderse en el tiempo y, por ello, es conveniente hablar de un proceso de larga duración.

Así pues, la cuestión de la integración se plantea en los distintos países de acogida a causa de la importancia que ha adquirido el fenómeno migratorio. Esta importancia varía en función de diversos parámetros, de los cuales el principal es el volumen de la inmigración.

1 El asesinato del cineasta Théo Van Gogh por parte de un joven neerlandés de origen marroquí reanimó con cierta pasión el debate sobre esta cuestión. 


\section{DE UNA INMIGRACIÓN DE MANO DE OBRA A UNA INMI- GRACIÓN SEDENTARIZADA}

De los 180 millones de emigrantes que hay actualmente en el mundo, la Unión Europea acoge a unos 19 millones. Una parte importante de los emigrantes reside en los países en desarrollo: 71 millones, es decir, aproximadamente el $1,5 \%$ de sus 4.900 millones de habitantes, frente al $8,7 \%$ en los países desarrollados, pero con el matiz de que este último porcentaje incluye las migraciones entre países ricos. Los pobres siguen siendo una proporción importante en los países pobres y no tienen los medios para emigrar hacia el Norte.

En los 15 de la Unión Europea, se calcula que, de los 19 millones de inmigrantes que viven en situación regular, cerca de un tercio (6 millones) son ciudadanos del espacio comunitario y 13 millones son ciudadanos de países no comunitarios $(68 \%)$.

La población musulmana surgida, de más de 40 años, de flujos migratorios, representa unos 12 millones de personas ${ }^{2}$. La mayoría son originarios del Magreb, de Turquía y de Pakistán. Más del 70\% viven en tres países: Alemania (sobre todos los turcos), Francia (sobre todo los magrebíes) y el Reino Unido (sobre todos los pakistaníes).

Los marroquíes, cerca de 2,5 millones de personas, representan más del $13 \%$ de la población extranjera en los países de la Unión Europea. No obstante, conviene recordar que se trata de una aproximación, pues el número de marroquíes en Europa es difícil de evaluar, dado el efectivo cada vez más importante de naturalizados y de la importancia de los flujos clandestinos.

La formación de una masa de inmigración relativamente importante ha hecho más visible la presencia de inmigrantes en los países de acogida $\mathrm{y}$, bajo la presión de una parte de la opinión pública refractaria y de un desempleo importante, esto ha llevado a determinados países de acogida a adoptar una política de ayuda al regreso.

Este regreso de los inmigrantes a su país se presenta como un medio para reducir el número de inmigrantes, incluso de detener la inmigración y así evitar problemas de inserción debido a su heterogeneidad social y cultural.

Sin embargo, hay que constatar que el proyecto migratorio para la mayoría de los emigrantes se ha convertido en un proyecto de vida. Esta transformación ha tenido lugar bajo el efecto del reagrupamiento familiar y como consecuencia de las diferenciaciones que registran los indicadores socio-económicos que se acentúan entre el país de acogida y el país de origen (salario, nivel de vida, cobertura social,...). El regreso interesa principalmente a los países de acogida tradicionales en los que residen los primeros emigrantes, es decir, la primera generación que ha llegado a la edad de la jubilación. Los emigrantes recientes, así como la segunda y la tercera generación, considerando principalmente las dificultades de reinserción en el país de origen, prefieren quedarse en los países de acogida. 
No existen estadísticas sobre el regreso. Para el caso marroquí, las escasas indicaciones disponibles son las de la encuesta realizada por el Instituto Nacional de Estadística y Economía Aplicada, datos que hay que manipular con prudencia.

TABLA 1. Intención de restablecerse en Marruecos

\begin{tabular}{|r|c|c|c|c|}
\hline CONDICIÓN & sí & NO & NO SABE & TOTAL \\
\hline Emigrante & 81,7 & 17,5 & 0,8 & 100 \\
Cónyuge & 73,3 & 24,1 & 2,6 & 100 \\
Hija & 35,0 & 37,2 & 27,8 & 100 \\
Hijo & 35,5 & 37,3 & 27,2 & 100 \\
\hline
\end{tabular}

INSEA: Los marroquies que residen en el extranjero. Op. cit, p147.

El porcentaje de "sí" nos parece exagerado y probablemente condicionado por el contexto de desarrollo de la encuesta, ya que se realizó en los "ferrys" que cruzan el Estrecho y que transportan a los emigrantes que vuelven a su país para pasar las vacaciones. Por tanto, la encuesta parece parcial por dos factores: no ha llegado a los que no vuelven al país y quizá se ha visto alterada por el estado psicológico del emigrante en el momento de "poner pie" en su país, momento propicio para favorecer el "sí".

Con estas reservas y según las conclusiones de la encuesta, las condiciones de regreso evocadas por los emigrantes están más relacionadas con la jubilación $(44,3 \%)$ y las condiciones favorables de inversión $(55,2 \%)$.

TABLA 2. Condiciones de regreso a Marruecos

\begin{tabular}{|r|c|c|c|}
\hline CONDICIONES & Sí & NO & TOTAL \\
\hline Jubilados & 44,5 & 55,5 & 100 \\
Estructura de acogida para los hijos & 13,0 & 87,0 & 100 \\
Escolarización & 11,7 & 88,3 & 100 \\
Formación & 9,3 & 90,7 & 100 \\
Condiciones favorables para invertir & 55,2 & 44,8 & 100 \\
Otras condiciones & 21,4 & $78,-$ & 100 \\
\hline
\end{tabular}

INSEA: Los marroquies que residen en el extranjero: una encuesta socioeconómica. INSEA. 2000, p147.

Las justificaciones evocadas por los emigrantes en relación con su intención de regresar muestran especialmente un apego al país de origen $(47,9 \%)$ o a la familia $(26,0 \%)$.

Sea como sea, estos valores parecen más fiables para considerar en los casos de provincias de emigración antigua que en las provincias de emigración reciente, dominadas por la partida de emigrantes en situación irregular, que es precisamente el caso de las provincias que alimentan los flujos migratorios con destino a países como España o Italia (en particular Tadla y Chaouia), donde el emigrante clandestino asume un coste cada vez más elevado para acceder a los países de acogida y es menos propenso al regreso.

Es importante constatar que la cuestión de la aplicación de una política de regreso no ha estado seguida de efectos notables. Dado que el proyecto migratorio se ha hecho definitivo y que las políticas de regreso no han tenido mucho 
efecto, se plantea la cuestión de la integración del inmigrante en las estructuras económicas, sociales y políticas del país de residencia.

\section{LOS ESPACIOS DE INTEGRACIÓN}

En general, se distinguen cuatro espacios de integración: económico, social, político y cultural.

\subsection{El espacio económico}

Históricamente, la mano de obra extranjera durante mucho tiempo se concentró en los sectores menos atractivos para la mano de obra nacional y que exigían pocas titulaciones (las actividades de las 3 D: dirty, dangerous, degrading). Se trata, en particular, de la construcción y las obras públicas, la minería, la agricultura y de ciertas industrias como el automóvil y los textiles, así como ciertas actividades del terciario: basureros, limpia cristales, servicios domésticos...

Así pues, la gran mayoría de los trabajadores inmigrantes se encuentran en las categorías de obreros no cualificados o poco cualificados. Esta "dinámica de los oficios mediocres" ha permitido seguir empleando a trabajadores extranjeros con un salario inferior al que habría exigido la mano de obra autóctona, lo que refuerza las desigualdades de base entre los trabajadores nacionales y extranjeros, ampliando así la concentración de estos últimos en determinados sectores o segmentos de sectores económicos y en ciertas categorías socio-profesionales.

En España, hay que recordar que, según la legislación en vigor, la concesión de un permiso de trabajo a los extranjeros está condicionada por la situación de empleo de los españoles. Los permisos de trabajo sólo se conceden para los empleos de actividades en las que existe una necesidad de mano de obra o que son rechazados por la mano de obra española ${ }^{3}$.

El hecho de que las medidas de regularización y la política de contingentes tomen en cuenta estas presiones explica la fuerte concentración de emigrantes marroquíes en determinados sectores de actividad.

Los sectores de actividad que contratan a los marroquíes son: la agricultura, con cerca del $37 \%$, los servicios $35 \%$, la construcción $15,5 \%$, la industria $8 \%$ y el resto de las actividades cerca del $5 \%{ }^{4}$. En general, son empleos sin titulación o muy poco cualificados, empleos de temporada (agricultura, turismo) o que dependen en gran medida de la coyuntura económica (construcción), que no ofrecen garantías jurídicas ni laborales (servicios domésticos). Estos empleos están entre los más desfavorecidos del mercado de trabajo español y

3 Colectivo IOE, 1998: "La política migratoria en España después de las elecciones de 1996". Migración y Sociedad, vol 10, n57. mayo-junio.1998.

4 Según ciertas estimaciones relativas a toda la población inmigrante, los servicios domésticos representan entre el $21 \%$ y el $23 \%$ del empleo total de los emigrantes, frente a menos del $3 \%$ del empleo de los nacionales, la restauración representa del 14\% al 18\% del empleo de los emigrantes frente al $6 \%$ del empleo de los nacionales. Cf. A Izquierdo Escribano: Inmigración; mercado de trabajo y protección social en España. CES. Colección Estudios. 2003, p 192. 
se caracterizan por un fuerte índice de temporalidad, muy frecuente en la construcción (57\% de los contratos), los servicios de limpieza (49\%), los servicios domésticos $(47 \%)$ y la hostelería (46\%).

TABLA 3. Distribución sectorial de los trabajadores marroquíes (\%)

\begin{tabular}{|r|l|l|l|l|l|l|l|l|}
\hline SECTORES & \multicolumn{1}{|c|}{$\mathbf{1 9 9 2}$} & \multicolumn{1}{|c|}{$\mathbf{1 9 9 3}$} & \multicolumn{1}{|c|}{$\mathbf{1 9 9 4}$} & \multicolumn{1}{|c|}{$\mathbf{1 9 9 5}$} & \multicolumn{1}{|c|}{$\mathbf{1 9 9 6}$} & \multicolumn{1}{|c|}{$\mathbf{1 9 9 7}$} & \multicolumn{1}{|c|}{$\mathbf{9 9 8}$} & \multicolumn{1}{c|}{$\mathbf{9 9 9}$} \\
\hline Agricultura & 24,0 & 24,7 & 23,5 & 30,0 & 33,6 & 36,2 & 37,3 & 36,8 \\
Industria & 8,9 & 9,5 & 8,4 & 8,3 & 7,9 & 8,1 & 8,0 & 8,0 \\
Construcción & 24,8 & 21,6 & 16,4 & 16,3 & 15,3 & 15,1 & 14,0 & 15,5 \\
Servicios & 41,9 & 44,2 & 37,3 & 36,8 & 35,5 & 35,3 & 35,7 & 35,1 \\
No clasif. & 0,4 & 0,0 & 14,4 & 8,5 & 7,8 & 5,3 & 5,0 & 4,6 \\
\hline TOTAL & 100 & 100 & 100 & 100 & 100 & 100 & 100 & 100 \\
\hline
\end{tabular}

FUENTE: Anuario de Migraciones $2000 \& 2002$.

Pero si la población activa extranjera sigue caracterizándose por la gran proporción de obreros, en los últimos años se aprecia una evolución cualitativa notable marcada especialmente por:

- la feminización creciente de la población activa inmigrante,

- la terciarización incrementada del empleo, lo que confirma, por ejemplo, la proporción de inmigrantes marroquíes que trabajan en el grupo de actividades de "comercio, transportes, servicios" y

- una diversificación real, aunque todavía no lo suficientemente delimitada, de las formas de empleo inmigrante. En efecto, asistimos en la actualidad a un desarrollo del empleo no asalariado, asociado a un trabajo independiente y a la creación de empresas en determinados sectores y determinadas regiones. La situación varía de un país a otro. En Francia, por ejemplo, se calcula que cerca del 10\% de los empresarios son extranjeros. De entre ellos, 2 de cada 3 vienen del sur de Europa o del Magreb ${ }^{5}$.

En España, los empleos altamente cualificados ocupados por los extranjeros son relativamente importantes $(17,2 \%)$. Esto se explica por la presencia de inmigrantes de origen comunitario, principalmente ingleses, alemanes y holandeses. Los empleos de la categoría "Dirección de empresas y administraciones públicas" y "Técnicos y profesionales científicos e intelectuales" ocupados por marroquíes son poco numerosos $(1,9 \%)$. En cambio, existe una concentración en los empleos de baja gama. La tabla de la página siguiente desglosa por profesión los empleos ocupados por los marroquíes en España.

No obstante, esta integración de los inmigrantes marroquíes en el mercado de trabajo de los países de acogida se enfrenta a distintos obstáculos y se lleva a cabo de manera diferente según las categorías que se distinguen por su estatus jurídico y social:

- los inmigrantes que entran clandestinamente en los países de acogida se diferencian por su estatus de ilegalidad. Estos inmigrantes ocupan empleos

5 Véase Mohamed Khachani: Les Marocains d'ailleurs: la question migratoire à l'épreuve du partenariat euro-marocain, p. 163. 
TABLA 4. Reparto por profesiones de los trabajadores marroquíes y extranjeros (1999)

\begin{tabular}{|c|c|c|c|c|}
\hline & 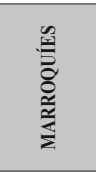 & 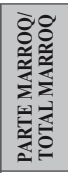 & 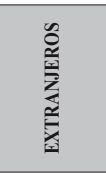 & 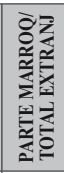 \\
\hline Dirección de empresas y Administraciones Públicas & 1.333 & 1,7 & 9.530 & 14,0 \\
\hline Técnicos y profesionales científicos e intelectuales & 157 & 0,2 & 4.938 & 3,2 \\
\hline Técnicos profesionales de apoyo & 258 & 0,3 & 4.627 & 5,6 \\
\hline Empleados de tipo administrativo & 385 & 0,5 & 3.364 & 11,4 \\
\hline Servicios de restauración, protección y seguridad & 4.357 & 5,7 & 21.231 & 20,5 \\
\hline Empleados en el comercio y asimilados & 1.628 & 2,1 & 4.936 & 33,0 \\
\hline Trabajadores cualificados en agricultura y pesca & 895 & 1,2 & 1.234 & 72,5 \\
\hline $\begin{array}{l}\text { Trabajadores cualificados en la construcción (operadores de } \\
\text { máquinas no incluidos) }\end{array}$ & 3.685 & 4,8 & 6.053 & 60,9 \\
\hline $\begin{array}{l}\text { Trabajadores cualificados en la industria minera, } \\
\text { metalurgia, construcción de máquinas y asimilados }\end{array}$ & 867 & 1,1 & 3.222 & 26,9 \\
\hline $\begin{array}{l}\text { Trabajadores cualificados en las artes gráficas, el textil y la } \\
\text { confección, la alimentación, artesanos y asimilados }\end{array}$ & 2.206 & 2,9 & 4.344 & 50,8 \\
\hline $\begin{array}{l}\text { Operadores de instalaciones y máquinas de motor y } \\
\text { conductores }\end{array}$ & 744 & 1,0 & 2.472 & 30,1 \\
\hline Empleados domésticos y personal de limpieza & 11.235 & 14,7 & 55.001 & 20,4 \\
\hline $\begin{array}{l}\text { Vendedores ambulantes y asimilados, conserjes y otros } \\
\text { trabajadores no cualificados en los demás sectores }\end{array}$ & 4.571 & 6,0 & 8.790 & 52,0 \\
\hline Obreros agrícolas y de la pesca & 31.888 & 41,6 & 41.434 & 77,0 \\
\hline Obreros de la construcción & 8.084 & 10,5 & 11.861 & 68,2 \\
\hline $\begin{array}{l}\text { Obreros de las minas, las industrias manufactureras y del } \\
\text { transporte }\end{array}$ & 4.345 & 5,7 & 8.729 & 49,8 \\
\hline No clasificados & 3.805 & 5,0 & 7.942 & 47,9 \\
\hline TOTAL, EXCLUIDOS LOS NO CLASIFICADOS & 76.638 & 100 & 191.811 & 40 \\
\hline
\end{tabular}

FUENTE: MTAS: Estadisticas de los permisos de trabajo de los extranjeros.

más precarios (servicios domésticos, agricultura, restauración...) y perciben salarios más bajos por horarios laborales más largos.

- Los inmigrantes de corrientes migratorias antiguas, los primeros inmigrantes, experimentan a menudo una situación precaria en el mercado laboral y no se distinguen de los clandestinos más que por la legalidad de su estancia.

- Los inmigrantes naturalizados que están “difuminados” entre los autóctonos gracias a la naturalización se prestan difícilmente a los estudios, pero están relativamente más aventajados por su estatus.

- La segunda generación (y cada vez más la tercera) se distingue, en cambio, por un nivel de enseñanza y de aspiraciones más elevado. Los jóvenes de esta generación se dirigen principalmente hacia el terciario estructurado (comercio, banca...) y hacia los empleos de la función pública para los naturalizados. 
- Los inmigrantes diplomados. Aunque ocupen una posición privilegiada, su llegada conduce a menudo a una bajada de clase pronunciada o duradera, dadas las condiciones actuales del mercado laboral.

- Por último, los altos cargos (investigadores en los laboratorios, profesores, ejecutivos de empresas...), cuya cifra evoluciona bajo los efectos de la fuga de cerebros. Marruecos, a semejanza de otros países en desarrollo, sufre una auténtica hemorragia de competencias ${ }^{6}$.

\subsection{El espacio social}

En el proceso de integración, la vivienda y la institución escolar desempeñan un papel primordial: el paso de una inmigración de mano de obra a una inmigración sedentarizada ha tenido como consecuencia que la vivienda se convierta en un punto clave de la integración. Esto afecta en particular a la vivienda social, y en ese nivel es donde la aceptación de la convivencia de los autóctonos con las familias inmigrantes es menos fácil.

La vivienda es determinante para la integración social, en la medida en que por su tamaño, sus características y su entorno facilita o compromete la reagrupación familiar, que sabemos constituye actualmente el modo de vida de un número creciente de inmigrantes. Sin embargo, la vivienda también es determinante en la medida en que condiciona la calidad de reproducción de la fuerza de trabajo y controla el acceso a cierto número de prestaciones, en especial de ayuda social o de servicios, tales como los servicios escolares.

Con respecto a esta exigencia primordial de vivienda, no podemos sino deplorar la existencia de una oferta particularmente restrictiva para los inmigrantes. Más que la competencia en el mercado de trabajo, es la convivencia en las mismas zonas residenciales lo que ha alimentado, en especial en la clases populares que están en el mismo barco, el sentimiento de regresión y asimilación a los que antes considerábamos como la capa social más desfavorecida. La reagrupación familiar y la fuerte concentración en algunas regiones y en el interior de las ciudades en algunos barrios avivan esta percepción de la inmigración como "invasión". En Francia, a partir de los años 70 se inició un debate sobre "el umbral de tolerancia" que implícitamente inspira la elección en materia de vivienda de los inmigrantes. La división de estos jóvenes que "sostienen las paredes" en las afueras de las ciudades francesas es un gran reto para la integración de los inmigrantes en ese país.

La institución escolar, lugar de acumulación de los conocimientos y del aprendizaje del razonamiento, también es un lugar de socialización. En ese sentido, puede favorecer una movilidad social ascensional.

El derecho a la educación escolar para todos, independientemente del origen y de cualquier otra característica personal o familiar, está reconocido en los distintos países de acogida. Está ratificado en el convenio europeo para la protección de los derechos humanos y de las libertades fundamentales.

6 Mohamed Khachani: "L'émigration élitiste Sud-Nord: le cas du Maroc". In Annuaire de la Méditerranée 2001. Publications du GERM. Rabat 2002. 
Las estadísticas escolares no describen la situación escolar de los hijos de inmigrantes, no obstante, la idea extendida es que los hijos de inmigrantes se enfrentan a dificultades.

Estas dificultades se ven alimentadas por los modos de vida de las familias extranjeras desfavorecidas. Sus formas de implicación en la escolaridad de sus hijos y sus "esfuerzos educativos" en cuanto a tiempo y dinero parecen, sin embargo, influidos por las condiciones materiales y sociales difíciles de su vida. Al no disponer de nivel escolar y, por ello, a veces analfabetos, en general están en una situación de eclipsación y de delegación en cuanto a la institución escolar; rara vez ayudan a sus hijos a hacer los deberes y no asisten, o muy poco, a las reuniones de clase.

La escolarización de los hijos de inmigrantes es una cuestión compleja, debido también a la diversidad cultural de la masa migratoria. Esta diversidad culturar exige por parte de los profesores "una pedagogía intercultural". Esta podría definirse como el conjunto de los medios finalizados que permiten a los profesores cumplir con la orden común: "La tarea del profesor debería ser la de buscar cualquier medio de valorizar a cualquiera de sus alumnos explorando todo lo posible todas sus aptitudes con el fin de descubrir las que servirán de palanca para su acción de formación. Una evolución así de su acción pasa por un conocimiento suficiente de la psicología de los jóvenes, por un reconocimiento de su entorno sociocultural ". En la práctica de esta pedagogía, el hecho de tener en cuenta la especificidad cultural del alumno es una exigencia fundamental. No obstante, estas condiciones están lejos de cumplirse en los países de acogida.

Asimismo, en materia de orientación del alumno, si en algunos países tenemos tendencia a privilegiar la reproducción del modelo social de los padres y a orientar al hijo a menudo hacia la enseñanza profesional, asistimos cada vez más a un rechazo consciente de la segunda y tercera generación a reproducir este modelo. Esta evolución ha contribuido al surgimiento de una elite inmigrante que se implica en distintos campos de estudio a veces con situaciones de excelencia.

\subsection{El espacio político}

La participación en la vida política del país de acogida desde luego no es obvia. Desde siempre, la vida de la ciudad era un ámbito reservado únicamente a los ciudadanos y no es una casualidad si en el antiguo Derecho Romano la palabra "hostis" designaba, en las doce tablas de Roma, a la vez al extranjero y al enemigo. Además, no hay que extrañarse al constatar que la actividad política de los extranjeros está sometida, por lo general, a una normativa severa. En todas las sociedades, un gran número de derechos y libertades siguen estando vinculados a la nacionalidad de la persona. Hoy en día, el extranjero se encuentra, por definición, en una situación de "menos derecho" o de "infra-derecho" que es discriminatoria por naturaleza. No obstante, se observan grandes diferencias de un país a otro.

7 Commission "Education- Formation- Recherche" du Xème Plan. Citée in. Françoise Lorcerie: "Scolarisation des enfants d'immigrés". CONFLUENCES: Les immigrés, entre exclusion et intégration. Edit Eddif. 1995. 
Desde 1963, los extranjeros votan en las elecciones locales en Irlanda. Este derecho se instituyó en 1975 en Suecia, en 1981 en Dinamarca, en 1985 en Noruega y en los Países Bajos y en 1996 en Finlandia. En el Reino Unido, desde 1948, los ciudadanos de la Commonwealth participan en todas las elecciones. Algunos cantones suizos han concedido pronto a los residentes extranjeros, fuere cual fuere su nacionalidad, el derecho de voto y el derecho a la elegibilidad a nivel local y regional. España y Portugal aplican desde hace varios años este derecho supeditado a la reciprocidad. Portugal concedió el derecho de voto a todos los niveles con reciprocidad para los brasileños (1971) y los caboverdianos (1997) y concede el derecho de voto local con algunas condiciones para los países lusófonos. Otros países, en cambio, no reconocen a los inmigrantes el derecho a la participación política, incumpliendo así las resoluciones del Parlamento Europeo que interpela a los Estados miembros sobre la cuestión de la legitimidad democrática. Una de estas resoluciones expresa el deseo de que "de conformidad con los principios democráticos fundadores de la Unión Europea, los Estados miembros adapten su legislación, a la mayor brevedad, con vistas a hacer extensivo el derecho de voto y la elegibilidad en las elecciones municipales y europeas al conjunto de los ciudadanos extracomunitarios que residan desde hace más de cinco años en su territorio". ${ }^{8}$

Otras iniciativas van en la misma dirección: en Francia, en diciembre de 1998, el MRAP y la Federación Léo Lagrange lanzan la petición: "Mismo suelo, mismos derechos, misma voz" y en marzo de 2000, las asociaciones surgidas de la inmigración lanzan la petición: “Un(a) residente, una voz". Por su parte, la Federación de Trabajadores Marroquíes en Francia ha reivindicado, en varias ocasiones, el derecho de voto para los extranjeros como un derecho democrático.

En realidad, este derecho hace referencia a una democracia de proximidad en la que la comunidad local se hace extensible a todos los que viven en ella, sin excluir arbitrariamente a determinadas categorías ${ }^{9}$.

Pero este derecho tiene sus detractores. La idea a menudo sostenida para refutar esta integración política es el riesgo que representa una cultura diferente en cuanto a potencialidad de conflictos. Gilles Robien refuta esta idea ampliamente extendida afirmando que: "Los europeos quizá tengan la misma cultura, pero a menudo se han burlado de ella" ${ }^{10}$. Esta actitud ha sido confirmada por el Tratado de Ámsterdam que ha institucionalizado esta discriminación con respecto a los extracomunitarios, limitando el derecho de voto únicamente a los ciudadanos de los países europeos.

Inscribiéndose en esta lógica, cada vez más marroquíes adquieren la nacionalidad del país de acogida. Esta tendencia es perceptible en distintos países de acogida: en Bélgica, donde 63.000 marroquíes se convirtieron en ciudadanos

8 Véase Houria Alami: "Migration, citoyenneté politique et intégration culturelle: le cas de la France". In Migration et citoyenneté. Publications de l'AMERM . Rabat.2003.

9 A este respecto, cabe recordar que el eslogan oficial que incitaba a votar en las elecciones europeas de junio de 1999 afirmaba: "En Europa, hoy en día, votar es existir" y que un autor como Abdelmalek Sayad escribe sobre esto: "Existir es existir políticamente". Presse et immigrés en France, n 135/136, CIEMI. Nov-Déc. 1985.

10 Le Monde, 5 de mayo de 2000. 
belgas entre 1985 y 1997, en los Países Bajos, donde 86.688 personas adquirieron la nacionalidad neerlandesa entre 1994 y 2000 y donde el $27 \%$ de los extranjeros naturalizados en el 2000 eran marroquíes, y en Francia, donde la naturalización ha evolucionado así entre 1989 y 1999.

TABLA 5. Marroquíes que han adquirido la nacionalidad francesa (1989-1999)

\begin{tabular}{|r|c|c|c|c|c|c|c|c|c|c|c|}
\hline AÑO & $\mathbf{1 9 8 9}$ & $\mathbf{1 9 9 0}$ & $\mathbf{1 9 9 1}$ & $\mathbf{1 9 9 2}$ & $\mathbf{1 9 9 3}$ & $\mathbf{1 9 9 4}$ & $\mathbf{1 9 9 5}$ & $\mathbf{1 9 9 6}$ & $\mathbf{1 9 9 7}$ & $\mathbf{1 9 9 8}$ & $\mathbf{1 9 9 9}$ \\
\hline Por decreto & 2.230 & 3.220 & 4.577 & 5.539 & 5.690 & 12.575 & 6.063 & 8.117 & 8.427 & 8.694 & 11.292 \\
Por declaración & 3.163 & 4.521 & 5.712 & 6.753 & 7.442 & 10.101 & 2.515 & 2.551 & 2.840 & 2.989 & 3.375 \\
\hline TOTAL & 5.393 & 7.741 & 10.289 & 12.292 & 13.132 & 22.676 & 8.578 & 10.668 & 11.267 & 11.683 & 14.667 \\
\hline
\end{tabular}

FUENTE: Ministerio de empleo y solidaridad

En España, un número cada vez más importante de marroquíes solicita la nacionalidad española. Los marroquíes, junto con los argentinos, figuran entre los extranjeros más numerosos en adquirir la nacionalidad española desde 1985. En diez años, 10.706 marroquíes han obtenido la nacionalidad española; en 2001, representaban el $74 \%$ de los naturalizados originarios del continente africano y el 17\% del conjunto de las personas naturalizadas en España.

TABLA 6. Naturalización de marroquíes en España entre 1990 y 2001

\begin{tabular}{|r|c|c|c|c|c|c|c|c|c|c|c|c|}
\hline AÑOS & $\mathbf{1 9 9 0}$ & $\mathbf{1 9 9 1}$ & $\mathbf{1 9 9 2}$ & $\mathbf{1 9 9 3}$ & $\mathbf{1 9 9 4}$ & $\mathbf{1 9 9 5}$ & $\mathbf{1 9 9 6}$ & $\mathbf{1 9 9 7}$ & $\mathbf{1 9 9 8}$ & $\mathbf{1 9 9 9}$ & $\mathbf{2 0 0 0}$ & $\mathbf{2 0 0 1}$ \\
\hline Marroquíes & 1.675 & 427 & 597 & 987 & 897 & 785 & 687 & 1.056 & 1.542 & 2.053 & 1.921 & 2.822 \\
\hline Total África & 1.851 & 577 & 779 & 1.315 & 1.227 & 1.060 & 1.032 & 1.471 & 2.150 & 2.860 & 2.577 & 3.826 \\
\hline TOTAL GRAL. & 7.033 & 3.752 & 5.280 & 8.416 & 7.801 & 6.756 & 8.435 & 10.311 & 13.177 & 16.384 & 11.998 & 16.743 \\
\hline
\end{tabular}

FUENTE: Ministerio de Trabajo y AASS. Subdirección Gral. de Migraciones. Anuario de Migraciones 2002.

Otros marroquíes han contraído matrimonios mixtos para acceder a la nacionalidad. El caso español es revelador a este respecto. En 1999, el 14,3\% de las mujeres españolas casadas con extranjeros eligieron un cónyuge de nacionalidad marroquí (707) y el 10,1\% de los españoles de sexo masculino se casaron con mujeres marroquíes. En conjunto, de los 10.061 matrimonios mixtos, el $12,2 \%$ se celebraron con un ciudadano o ciudadana marroquí. ${ }^{11}$

¿Pero la adquisición de la nacionalidad realmente favorece la integración? Aunque desde un punto de vista jurídico los marroquíes naturalizados son considerados ciudadanos en el país de acogida, desde un punto de vista sociológico, siempre se asimilan al grupo étnico de origen. En efecto, aunque experimentan un proceso de integración, el cambio de estatus jurídico, en general, no altera (o altera poco) su modelo cultural y las relaciones sociales que mantienen con el grupo de origen.

El cambio de estatus jurídico no implica necesariamente el cambio de estatus social, en otras palabras, "la integración formal" no implica en absoluto "la integración real”. En efecto, algunos países están más adelantados que otros, y Bélgica constituye a este respecto un ejemplo a meditar, dada la innovación

$11 \mathrm{Cf}$, Fondation Hassan II pour les marocains résidant à l'etranger, OIM: Les marocains de l'Extérieur. Juillet 2003. P. 167. 
política registrada desde finales de los años 80 por parte de los belgas descendientes de inmigrantes.

El nombramiento en julio de 2003, aunque efímero, de Anissa Temsamani en el puesto de Secretaria de Estado para "la organización del trabajo y el bienestar en el trabajo" en el gobierno belga constituyó un acontecimiento importante que se inscribe en la prolongación de una implicación política cada vez más avanzada de los descendientes de inmigrantes. Este nombramiento abrió el camino, ya que el 18 de julio de 2004, Fadila Laanan, miembro del Partido Socialista, fue nombrada Ministra de Cultura, Medios Audiovisuales y Juventud en el gobierno de la Comunidad Francesa.

Las elecciones municipales de octubre de 1988 contaron por primera vez con candidaturas de descendientes de inmigrantes y con la elección de una consejera de origen marroquí en Amberes y las de 1994 registraban 85 candidatos de origen marroquí de los que 11 fueron elegidos. Durante las elecciones regionales de 1995, tres consejeros de origen marroquí fueron elegidos en el Consejo de la Región de Bruselas-capital. Pero fue durante las elecciones municipales de octubre de 2000 donde asistimos a una auténtica explosión del número de belgas de origen marroquí elegidos en los ayuntamientos, en particular en Bruselas, donde representaban el 10\% del conjunto de los representantes locales y algunos de ellos recibieron responsabilidades significativas en los ejecutivos municipales. Además, 7 concejales de origen marroquí fueron elegidos en Bruselas. ${ }^{12}$

TABLA 7. Representantes de origen marroquí en Bélgica el 1/08/2000 ${ }^{13}$

\begin{tabular}{|r|c|c|c|c|c|c|}
\cline { 2 - 7 } \multicolumn{1}{c|}{} & PS/SP-A & Ecolo-Agalev & CdH-CD\&V & MR-VLD & Otros & TOTAL \\
\hline Representantes locales en Bruselas & 33 & 29 & 3 & 9 & 2 & 76 \\
Concejales en Bruselas & 5 & 2 & - & - & - & 7 \\
Representantes regionales Parlamento de Bruselas & 3 & 2 & - & 2 & - & 7 \\
Representantes regionales Parlamento flamenco & 1 & - & - & - & - & 1 \\
Representantes federales (Cámara y Senado) & 5 & - & 1 & 1 & - & 7 \\
Ministros y Secretarios de Estado federales & 1 & - & - & - & - & 1 \\
\hline
\end{tabular}

FUENTE: www.suffrage-universel.be y datos propios del autor.

Las elecciones de junio de 2004 confirmaron este avance de la comunidad de origen marroquí. Por ejemplo, de los 72 representantes francófonos de Bruselas, 18 son de origen no-europeo (14 PS, 2 CDH, 1 MR-FDF, 1 Ecolo) de los cuales 12 representantes son de origen marroquí (10 PS, 1 MR-FDF, 1 $\mathrm{CDH})$. De los 17 representantes neerlandófonos de Bruselas: 1 de origen noeuropeo, Fouad AHIDAR, marroquí afiliado al SP.A-Spirit. En el parlamento

12 Hasan Bousetta: "Citoyenneté et participation politique: l'exemple des Belges d'origine marocaine à Bruxelles". En Migration et citoyenneté. Op. cit. En su gran mayoría, estos nuevos representantes municipales de Bruselas pertenecen a los partidos socialistas y ecologistas francófonos. Cuentan entre sus filas aproximadamente con un quinto de mujeres.

13 PS: Parti Socialiste (partido socialista); SP-A: Social Progressief Alternatief (partido socialista flamenco); $\mathrm{CdH}$ : Centre Démocrate Humaniste (Ex-Parti Social Chrétien) (centro demócrata humanista, antiguo partido social cristiano); CD\&V: Christen Democratisch en Vlaams (cristiano-demócratas flamencos); MR: Mouvement Réformateur (fédération de partis du centre et de droite) (movimiento reformador, federación de partidos de centro y derecha); VLD: Vlaamse Liberalen en Democraten (centro-derecha flamenco; partido del Primer Ministro Guy Verhofstad). 
flamenco, se eligió a Anissa Temsamani en Amberes y a Chokri Mahassine en Limburgo. En el parlamento federal, ocupa un escaño Mohammed Boukourna (PS). Asimismo, fueron elegidos senadores comunitarios: Sfia Bouarfa, Fouzya Talhaoui (partido flamenco Spa Spirit). Por último, como se indicaba anteriormente, un belga de origen marroquí ostenta la cartera ministerial, Fadila Laanan, Ministra de Cultura en la Comunidad Francesa de Bélgica.

Esta conquista del espacio político llega a otros países de acogida, como Francia, donde varios concejales municipales y miembros de los gabinetes ministeriales son de origen marroquí y donde dos ministros son de origen magrebí, Hamlaoui Mekechera, Secretario de Estado de los ex-combatientes, y Tokia Saïf, Secretaria de Estado de desarrollo sostenible.

Esta tendencia empieza a manifestarse incluso en los países de inmigración reciente, como España, donde Mohamed Chaib, de origen marroquí, acaba de ser elegido en el parlamento catalán (lista socialista) e Italia, donde el ciudadano marroquí Aziz Darif ha sido elegido miembro-adjunto del Consejo municipal de Roma ${ }^{14}$.

\subsection{El espacio cultural}

El concepto de la cultura es difícil de aprehender. Entre las numerosas definiciones del concepto, podemos quedarnos con la que considera que: "la cultura es todo lo que constituye el ser humano aparte de su aspecto biológico”. Según esta definición, la cultura del inmigrante aparece en sus actitudes, en su comportamiento, en su manera de actuar y de reaccionar. Los inmigrantes marroquíes en Europa tienen una personalidad cultural propia, que tiene derecho al respeto y que debe protegerse especialmente. Esta amenaza viene de la posición de debilidad en la que se encuentran los inmigrantes en el seno de la sociedad de acogida y es aún más real por tratarse de una categoría de derechos que no se sitúa a la cabeza de la jerarquía de lo que se intenta defender. Por delante del respeto de la cultura pasan la estabilidad laboral, la vivienda, la salud, la reagrupación familiar, etc.

Por lo tanto, no hay que extrañarse del descubrimiento tardío y de la reivindicación reciente de los derechos culturales, reivindicación que, en relación con los derechos culturales de los inmigrantes magrebíes en Europa, sigue suponiendo una problemática, pues interpela los fundamentos de toda ciencia jurídica y política y pone en tela de juicio la concepción universalista de los derechos humanos.

Este encuentro de la cultura del país de origen con la del país de acogida provoca, en efecto, un debate doctrinal pertinente entre los partidarios de la especificidad y los defensores de la universalidad. Los primeros reclaman "el derecho a la diferencia", los segundos el derecho a "la indiferencia". Cada corriente utiliza sus argumentos en los laberintos de la sociología jurídica, in-

14 En cuanto a Italia, estas elecciones pretenden asociar a los inmigrantes a la gestión de los municipios. Al final de las primeras elecciones de este tipo en la capital italiana, y según un comunicado del municipio de Roma, Aziz Darif representará a los inmigrantes provenientes del continente africano y ocupará el puesto con un rumano, una filipina y un peruano, que defenderán respectivamente los intereses de las comunidades europea, asiático-oceánica y americana. Véase http://www.wafin.be. 
cluso de la filosofía jurídica, que en un momento dado impregnaron los mismísimos fundamentos del derecho internacional privado.

\section{LOS OBSTÁCULOS PARA LA INTEGRACIÓN}

La integración nos remite a la dinámica de las relaciones y de las afiliaciones colectivas en los países de acogida, lo que Jacques Berque llamaba: "la dialéctica de lo unitario y de lo plural". La integración y la lucha contra la exclusión van a la par, la una condiciona a la otra. Ahora bien, lo que se observa es que la exclusión se mantiene en particular en el ámbito del trabajo y en el ámbito social. Por tanto, una vez salvadas "las fronteras externas", el emigrante se enfrenta a "las fronteras internas" que son de orden económico, político y social. De hecho, las fronteras externas tan sólo constituyen un "espejismo", ya que en realidad las verdaderas fronteras son las barreras internas que marcan la diferencia entre los que están dentro de la sociedad y los que están fuera ${ }^{15}$.

\subsection{Discriminación en el mercado laboral}

Los cambios económicos en general han debilitado la posición de la mano de obra inmigrante en el mercado laboral de los países de acogida y generan tasas de desempleo de los inmigrantes superiores a las de los nacionales. El reparto de desempleados por nacionalidad no es regular: los magrebíes y los turcos son los más afectados.

En Bélgica, las probabilidades de acceder a un empleo se hacen cada vez más difíciles. Una serie de factores explica este desempleo masivo que se observa entre la población de nacionalidad marroquí: "El declive de los sectores antiguos y pesados de la industria que ofrecian hasta finales de los años 80 muchísimos empleos no cualificados, la falta de formación y de titulación profesional de estos trabajadores, la debilidad de las capacidades lingüísticas, en un país donde el bilingüismo francés-neerlandés a menudo se exige, la pobreza del capital social de las familias inmigrantes, que no siempre disponen de redes de conocidos o amigos bien situados y bien informados que puedan facilitar el acceso al empleo, la discriminación en la contratación es practicada por numerosos empresarios" $"$.

En Francia, se estima que la cifra de desempleados marroquíes ascendía a 90.756 en 1999, una cifra superior en 34.500 a la de 1990, lo que representa un crecimiento anual medio del 5,3\%. Según el último censo francés, el 30,8\% de la población activa marroquí inmigrante está en paro, una tasa superior al conjunto de la población inmigrante $(22,0 \%)$.

Esta situación es mucho más problemática para los jóvenes y las mujeres.

El desempleo afecta en especial a los jóvenes. La tasa de desempleo es del $42 \%$ para el grupo etario de 15-19 años, de más del 44\% para el grupo etario

15 Cf. la tesis de María del Mar Bermúdez: Le mirage des frontières: Les migrations clandestines et leur contrôle en Espagne. Thèse IEP de Paris. Décembre 2004.

16 Office Régional Bruxellois de l'Emploi: «Populations issues de l'immigration, marché de l'emploi et discrimination: situation en région de Bruxelles capitale». Les Cahiers de l'Observatoire, $\mathrm{N}^{\circ} 3$, juin 2000, P 63 . 
20-24 años y del 37\% para el grupo 25-29 años. Las mujeres se ven más afectadas por el desempleo que los hombres: $38 \%$ (frente al 27\% para el conjunto de la población inmigrante), y dicha tasa supera el 50\% para el grupo etario de 1519 años y alcanza el 46,5\% para el grupo de 20-24 años. ${ }^{17}$ El número de desempleados que nunca ha trabajado es relativamente elevado: 18.346 personas.

TABLA 8. Desempleo de los inmigrantes según la edad

\begin{tabular}{|r|c|c|}
\hline GRUPO ETARIO & $\begin{array}{c}\text { TASA DE PARO } \\
\text { INMIGRANTES MARROQUíES }\end{array}$ & $\begin{array}{c}\text { TASA DE PARO } \\
\text { INMIGRANTES }\end{array}$ \\
\hline $\mathbf{1 5 - 1 9}$ años & 41,9 & 36,6 \\
$\mathbf{2 0 - 2 4}$ años & 44,4 & 34,6 \\
$\mathbf{2 5 - 2 9}$ años & 37,1 & 28,1 \\
30-34 años & 32,9 & 23,9 \\
\hline 35-39 años & 29,3 & 21,0 \\
40-44 años & 28,1 & 19,6 \\
45-49 años & 25,7 & 18,8 \\
50-54 años & 26,4 & 18,7 \\
\hline 55-59 años & 29,6 & 22,7 \\
60 y más años & 24,0 & 17,8 \\
\hline TOTAL & 30,8 & 22,0 \\
\hline
\end{tabular}

FUENTE: Censo General de la Población en 1999.

En los Países Bajos, la tasa de desempleo que en 1994 alcanzaba el 31\% para los marroquíes, no superaba el 6,4\% para los autóctonos. Es cierto que ha bajado, pero se mantiene en un nivel relativamente elevado: 13\% en 2000.

Esta discriminación, cuya intensidad difiere según el país, se explica por la "preferencia nacional", la desigualdad de las oportunidades, la marginalización y la exclusión que sufre una parte importante de la comunidad marroquí en los países de acogida, lo cual deja sin sustancia a este respecto las distintas convenciones firmadas entre Marruecos y estos países y en particular el artículo 64 del acuerdo de asociación con la Unión Europea.

Los resultados de una encuesta realizada en 1997 en Bélgica, país en el que los marroquíes constituyen la primera comunidad extranjera, por la Oficina Internacional del Trabajo demostró que, con competencia igual, el 40\% de los jóvenes de origen extranjero en Flandes, el 34\% en Bruselas y el 27\% en Valonia eran víctimas de racismo en las distintas fases de la contratación, y que la selección se realiza en 3 niveles: el nombre, la entrevista de trabajo y la decisión.

Con la crisis, los inmigrantes clandestinos que, incluso apreciados por las ventajas que otorgaba su estatus en el mercado laboral (disponibilidad, flexibilidad y coste), se perciben en los discursos políticos, en los medios de comunicación y en la opinión pública como ilegales que amenazan el orden público. La política migratoria en Europa centra sus esfuerzos en la lucha contra la emigración clandestina, pues las sumas destinadas a este fin en algunos

17 Cf, Fondation Hassan II pour les marocains résidant à l'etranger, OIM: Les Marocains de l'Extérieur. Op.cit, $\mathrm{p} 251$. 
países como España superan con mucho el presupuesto destinado a favorecer la integración de los inmigrantes en situación regular.

Este contexto acentúa el déficit que sufren los marroquíes en materia de derechos humanos y que se manifiesta en el racismo, incluso en el odio y la violencia de los que son víctimas aquí y allá los inmigrantes marroquíes.

\subsection{Discriminación en el ámbito social: El racismo}

Es cierto que ningún factor por sí solo tiene un efecto tan peligroso para la integración de los inmigrantes como el racismo. En relación con esta actitud de rechazo, la gran encuesta realizada por el Observatorio Europeo del Racismo y la Xenofobia en 1997, año decretado "Año europeo contra el racismo" proporcionó "información muy preocupante en cuanto a la percepción del racismo y la xenofobia en Europa". En comparación con los resultados del año 1989, se observa que el racismo progresa entre la población europea; cerca del 33\% de las personas interrogadas se declaran abiertamente "bastante racista" o "muy racista" y el $41 \%$ de los europeos declaran que les parecen demasiadas las minorías étnicas de otra nacionalidad, religión o cultura que viven en su país (frente al $37 \%$ en 1989).

Los inmigrantes sufren la segregación tanto social (etiquetaje, estigma, umbral de tolerancia...) como espacial (barrio en el que viven,...) y esto se traduce en la multiplicación de comportamientos discriminatorios, no sólo en las relaciones laborales sino también en los servicios y las instituciones abiertos a los usuarios y a la clientela, en el acceso a la vivienda y en el beneficio de los derechos y ventajas sociales.

En Francia, un sondeo realizado en abril de 2002 revela que el 62\% de los franceses consideran "que hay demasiados inmigrantes en Francia"18. Mucho antes que los magrebíes, los españoles, los italianos y los polacos, entre otros, todos han conocido la intolerancia: denunciaban sus costumbres, su idioma e incluso sus creencias, tachando el catolicismo de "raro".

Si estos últimos comparten elementos de la cultura del país de acogida, este no es el caso de los marroquíes, para los cuales la emigración constituye en efecto un cambio cultural brutal y lo es aún más para sus hijos; éstos experimentan una división entre la cultura de pertenencia y la cultura de referencia (la de la sociedad de acogida) y se debaten así entre la socialización primaria (familia) y a la socialización secundaria (el entorno extra familiar).

Según una encuesta realizada por el INSEA en 1999, el 30,9\% de los inmigrantes marroquíes "declaran que se sienten más bien excluidos en las sociedades de acogida", exclusión que se experimenta a diferentes niveles. A la pregunta de si el emigrante o alguien de su familia ha sido objeto de un comportamiento racista o xenófobo, los emigrantes han contestado en afirmativa a razón de 29,1\% para el lugar de trabajo y 26\% para el barrio en el que viven.

Este sentimiento de exclusión puede producir dos actitudes diametralmente opuestas: el repliegue de identidad con todas sus implicaciones negativas

18 Esta fobia de la invasión afecta tanto a la "población de abolengo" como a las poblaciones de implantación reciente. Marianne 29 abril 2002: sondeo exclusivo CSA. 
a nivel de integración o actitudes de aculturación extrema. Algunos pueden esforzarse más por asimilarse al autóctono, incluso a costa de cambiar de apellidos y/o de nombres. En Francia, por ejemplo, el número de marroquíes de ambos sexos que decidieron cambiarse los apellidos y/o los nombres superó los 500 entre 1996 y 1999. Se trata en su gran mayoría de "afrancesamiento" del nombre, pues los "afrancesamientos" del apellido representan solamente entre el $10 \%$ y el $12 \%$ del conjunto ${ }^{19}$.

Pero lo que se observa es que las actitudes de exclusión y de rechazo del inmigrante son cada vez más perceptibles en países que se han convertido recientemente en países de inmigración como España e Italia.

En Italia, la estadística semestral de la Agenda degli italiani de 1998, elaborada por el CNEL (Consejo Nacional de Economía y Trabajo) conjuntamente con Eurisko, indica que, de una muestra de 2000 entrevistados, el 63\% declararon estar cada vez más preocupados por la llegada de extranjeros a Italia bajo el pretexto de que son la causa de los problemas de orden público y de que cogen los empleos de los italianos. Estas personas piden que el Estado demuestre una mayor firmeza frente a los extranjeros.

Los datos más significativos relativos al rechazo de los extranjeros se pueden resumir de la siguiente manera:

- El 80\% de los italianos piensa que los inmigrantes que viven en Italia son demasiado numerosos.

- El 75\% considera que las leyes que regulan la inmigración son demasiado laxistas.

- El 50\% tiene tendencia a pensar que hay que limitar la entrada de inmigrantes.

- El 33\% nunca se casaría con un(a) inmigrante.

- Al 25\% no le gustaría nada que su hija se casara con un inmigrante.

- El 10\% solo considera que los inmigrantes representan un recurso potencial.

\subsection{El caso de España}

Hablar de la inserción de los emigrantes supone la existencia de una política de integración que tenga en cuenta el estatus jurídico del trabajador marroquí y los aspectos humanos surgidos de una alteridad a menudo rechazada, los derechos fundamentales que se deben garantizar y las necesidades sociales que se deben satisfacer.

La antigüedad de esta comunidad en España no significa, sin embargo, que haya una buena integración. En al aspecto político, la Constitución española del 6 de diciembre de 1978 excluye a los extranjeros del derecho de voto y elegibilidad (art. 13), excepto para las elecciones municipales en caso de que, como se mencionaba, existan acuerdos de reciprocidad con el país de origen. Esta disposición se enmendó en 1992 para ampliar el derecho de voto en las elecciones municipales a los ciudadanos de los países de la UE.

19 Fondation Hassan II: Les Marocains de l'Extérieur. Op.cit,p 264. 
En cuanto a las condiciones de vida de la comunidad marroquí, estamos de acuerdo en afirmar que son precarias: vivienda, educación, salud, ocio. Las nuevas disposiciones de la Ley 8/2000 acentúan esta precariedad. A la vista de esta situación, se puede afirmar que los marroquíes constituyen uno de los segmentos "más pobres y más marginalizados de la población extranjera en España" ${ }^{20}$. Su integración se enfrenta a numerosos obstáculos.

La protección social de los inmigrantes sigue siendo limitada, en particular cuando se trata de inmigrantes en situación irregular. La encuesta realizada por ASEP/IMSERSO con una muestra de 750 inmigrantes clandestinos llega a las conclusiones siguientes:

TABLA 9. Ayudas y servicios recibidos por inmigrantes no comunitarios en 2000 (\%)

\begin{tabular}{|c|c|c|}
\hline & Sí & NO \\
\hline Ayuda a la vivienda & 6 & 92 \\
\hline Tarjeta sanitaria & 60 & 38 \\
\hline Asistencia sanitaria pública & 30 & 67 \\
\hline Subsidio de desempleo & 6 & 91 \\
\hline Cursos de español y de formación profesional & 12 & 84 \\
\hline Educación gratuita & 8 & 88 \\
\hline
\end{tabular}

La encuesta realizada por investigadores de la Universidad de La Coruña con una muestra de 3.094 inmigrantes en situación regular no ofrece las conclusiones siguientes:

\begin{tabular}{|r|c|c|}
\cline { 2 - 3 } \multicolumn{1}{c|}{} & Sí & NO \\
\hline Tarjeta sanitaria & 46,8 & 53,2 \\
Asistencia sanitaria & 46,8 & 53,2 \\
Niños escolarizados & 100 & - \\
Recurrir a un Centro de Servicios Sociales & 22,2 & 77,8 \\
\hline
\end{tabular}

FUENTE: citado en A. Izquierdo Escribano: Inmigración; mercado de trabajo y protección social en España, op. cit, p 271.

En general, los marroquíes se sienten excluidos en la sociedad española. En efecto, aunque los comunitarios y los demás europeos constituyen una parte relativamente importante de la masa migratoria, los que centran la atención de los poderes públicos, de la opinión pública y de los medios de comunicación son fundamentalmente los inmigrantes provenientes del Sur y, en particular, los marroquíes, los "moros" que encarnan en el imaginario colectivo el estereotipo de inmigrante.

Se desprende de las distintas encuestas realizadas periódicamente, en particular por el Centro de Investigaciones Sociológicas (CIS: estructura que depende del gobierno central) ${ }^{21}$, que la opinión pública establece un orden jerárquico de los extranjeros: los marroquíes junto con los africanos están clasificados debajo de la escala. "La imagen predominante del inmigrante siempre es, en

20 Giménez Romero, Carlos: "Marroquíes en España: un perfil sociocultural”. Atlas de la Inmigración Magrebí en España. Op.cit.

21 El barómetro del CIS de 2003 indica que el 58\% de los españoles asocian la inmigración y la inseguridad y que el $68 \%$ piensan que se les trata con desprecio, el 10\% con agresividad, el 1,7\% con recelo, el $45,5 \%$ con indiferencia. Véase El País del 10 de agosto de 2003. 
primer lugar, la del marroquí (...), los marroquies siguen siendo el grupo más afectado por los prejuicios y los estereotipos étnico-culturales "22 y que más sufre racismo y discriminaciones. Los acontecimientos de El Ejido que derramaron mucha tinta ${ }^{23}$ y los de Tarrasa revelan la intensidad de la xenofobia entre algunas categorías de la población y las dificultades de la sociedad española para adaptarse al nuevo orden de espacio de acogida.

Esta actitud de rechazo se ve duplicada por el fantasma de la invasión. Un sondeo publicado por el diario El País indica que el 80\% de los españoles temen una invasión de los inmigrantes durante los próximos años. Lo que preocupa de esta actitud es que este rechazo del "otro" es expresado incluso por los estudiantes, categoría social supuestamente más abierta y más tolerante. Una encuesta realizada por el sociólogo Tomás Calvo Buezas destacaba que, para el 56\% de los estudiantes madrileños, España debería “cerrar sus puertas a los extranjeros" y, para el $47 \%$ de los estudiantes encuestados, los inmigrantes son sinónimos de inseguridad y droga"24.

La escuela tiende a confirmar estas actitudes, pues el contenido de la enseñanza parece consagrar esta imagen negativa del "Otro". En efecto, el sistema educativo constituye un campo fértil para la producción de estereotipos, según lo confirma un estudio dirigido por Gema Martín Muñoz. Este estudio ha podido revelar todo lo que constituye una deformación ideológica de la imagen del "Otro": las lagunas, los prejuicios, los estereotipos, el vocabulario malintencionado y los falsos juicios de valores ${ }^{25}$.

Para integrarse mejor en la sociedad de acogida, una cifra cada vez más importante de marroquíes solicita la nacionalidad española. Los marroquíes, junto con los argentinos, figuran entre los extranjeros más numerosos en adquirir la nacionalidad española desde 1985. En diez años, 10.706 marroquíes han obtenido la nacionalidad española; en 2001, representaban el 74\% de los naturalizados originarios del continente africano y el 17\% del conjunto de personas naturalizadas en España.

TABLA 10. Las naturalizaciones de los marroquíes en España entre 1990 y 2001

\begin{tabular}{|c|c|c|c|c|c|c|c|c|c|c|c|c|}
\hline AÑOS & $\mathbf{1 9 9 0}$ & $\mathbf{1 9 9 1}$ & $\mathbf{1 9 9 2}$ & $\mathbf{1 9 9 3}$ & $\mathbf{1 9 9 4}$ & $\mathbf{1 9 9 5}$ & $\mathbf{1 9 9 6}$ & $\mathbf{1 9 9 7}$ & $\mathbf{1 9 9 8}$ & $\mathbf{1 9 9 9}$ & $\mathbf{2 0 0 0}$ & $\mathbf{2 0 0 1}$ \\
\hline Marroquíes & 1.675 & 427 & 597 & 987 & 897 & 785 & 687 & 1.056 & 1.542 & 2.053 & 1.921 & 2.822 \\
Total África & 1.851 & 577 & 779 & 1.315 & 1.227 & 1.060 & 1.032 & 1.471 & 2.150 & 2.860 & 2.577 & 3.826 \\
\hline TOTAL GENERAL & 7.033 & 3.752 & 5.280 & 8.416 & 7.801 & 6.756 & 8.435 & 10.311 & 13.177 & 16.384 & 11.998 & 16.743 \\
\hline
\end{tabular}

FUENTE: Ministerio de Trabajo y AASS. Subdirección Gral. de Migraciones. Anuario de Migraciones 2002.

22 Giménez Romero, Carlos: "Marroquíes en España: un perfil sociocultural”. Atlas de la inmigración magrebí en España. UA Ediciones. 1996.

23 Forum Civique Européen: El Ejido, terre de non droit. FCE-CEDRI, Bâle/Limans. 2000.

24 Cf./ Los resultados de la encuesta realizada en el entorno universitario en: Tomás Calvo Buezas: Inmigración y universidad. Prejuicios racistas y valores solidarios. Editorial Complutense 2001. Este rechazo del Otro se ve alimentado por un discurso político discriminatorio, como la declaración realizada en noviembre de 2000 por D. Enrique Miranda, entonces Secretario de Estado del Ministerio del Interior, encargado de la Inmigración y la Extranjería, que manifestaba la preferencia de su gobierno hacia los ciudadanos de los países cristianos, declaración que suscitó la indignación de las ONGs en España. Véase el comunicado de Servimedia del 07/11/2000; "ATIME califica de "peligrosa" la cautela del gobierno sobre la inmigración musulmana"(www.servimedia.es).

25 Gema Martín Muñoz (bajo la dirección): El Islam y el mundo árabe: guía didáctica para profesores y for- 
No obstante, al igual que se ha dicho para los otros países de acogida, aunque desde un punto de vista jurídico, los marroquíes naturalizados son considerados ciudadanos españoles, desde un punto de vista sociológico se les sigue considerando asimilados al grupo étnico de origen.

Sin embargo, conviene señalar que esta integración está diferenciada, ya que los que son originarios de la ex zona española de Protectorado, más impregnados de la cultura ibérica, muestran signos de inserción relativamente más fáciles que los demás marroquíes que provienen de otras regiones del país. Pero globalmente el estereotipo del "moro" sigue estando unido al perfil del emigrante marroquí.

\section{CONCLUSIÓN}

El inmigrante no debe percibirse solamente como el "otro", el extranjero, sino a la vez también como un trabajador que ha contribuido y que sigue contribuyendo a la expansión del país de acogida y como un ser humano que posee sus propias especificidades. Las aportaciones de la inmigración difícilmente se pueden medir, pero son totalmente reales. En España, el sindicato Comisiones Obreras ha intentado hacer una estimación de esta aportación, la cual ha revelado que los inmigrantes que trabajan en España generan entre el 2,5\% y el 4\% del PIB. Para el año 2000 (555.004 millones de euros) esto representa un valor añadido estimado entre 13.875 millones y 22.200 millones de euros ${ }^{26}$, es decir, de media más de 18.000 millones de euros, lo que equivale más o menos a la mitad del PIB marroquí (354.000 millones de dirhams en 2000). Esto debería incitar a descubrir la alteridad y la diferencia como relación y no como una barrera. Es peligroso tomar la vía del rechazo hacia el otro, pues esto en definitiva nos lleva de nuevo a la negación de uno mismo, porque cada uno siempre es el otro de los otros.

Para entender la alteridad como relación y vivir en convivencia con el "otro", "el diferente", hay que vivir y desarrollar la comunicación, el intercambio, el diálogo con todos los hombres, sin ninguna frontera (ni cultural, ni nacional, ni religiosa) en condiciones de libertad e igualdad. El respeto de la diferencia implica como condición esencial la lucha contra las desigualdades y las discriminaciones con el fin de que cada persona sea capaz de hablar y comunicarse y, de este modo, participar con sus particularidades y su identidad cultural en el enriquecimiento de la familia humana. En las sociedades pluriétnicas y pluriculturales, los extranjeros no deben ser percibidos como un problema que se debe resolver, sino como una oportunidad para explotar y un reto para asumir en la comunicación. El tercer punto de la Declaración de Bar-

madores. Agencia Española de Cooperación Internacional. Madrid. 1996. Véase nuestro comentario sobre esta obra In Liberation $n^{\circ} 2294$ del 23 de julio de 1998.

26 Secretariado de Migraciones-CGT de CCOO: "Tres notas sobre la aportación de los inmigrantes a la riqueza y al estado de bienestar". Madrid. Octubre 2000.

Cf también Mohamed Khachani "L'impact de l'immigration sur les pays d'accueil". Participation à la conférence AISO 2000: "Statistique, développement et droits de l'homme -Montreux- Suisse, 4-8 septembre 2000. 
celona insistía mucho sobre esta cuestión. Pero el balance de medidas tomadas a este respecto sigue siendo limitado.

La problemática de la integración sigue planteando múltiples problemas, algunos de ellos de gran complejidad. El diagnóstico rápido que hemos hecho de la situación puede incitar a invertir la cuestión y en lugar de preguntarse si el inmigrante marroquí es integrable, formular de otro modo esta pregunta y preguntarse si los europeos son capaces de acoger al otro. 